\title{
Chirurgische behandeling van een sublinguale sialocoele (ranula) bij een kat
}

\author{
Surgical treatment of a sublingual sialocele (ranula) in a cat
}

\author{
W. Verhoeven, A. Kitshoff, N. Devriendt, V. Dehuisser, H. de Rooster \\ Vakgroep Kleine Huisdieren, Faculteit Diergeneeskunde, Universiteit Gent, \\ Salisburylaan 133, B-9820 Merelbeke
}

Hilde.derooster@UGent.be

\section{AMENVATTING}

In deze casuïstiek wordt een zeven jaar oude, mannelijke, gecastreerde, Europese korthaar met een ranula beschreven. De patiënt werd aangeboden vanwege een sublinguale zwelling aan de rechterkant die chirurgisch werd behandeld door middel van marsupialisatie en excisie van de mandibulaire en sublinguale speekselklieren. Histopathologisch onderzoek van de verwijderde weefsels bevestigde de diagnose van een ranula en toonde de onopzettelijke resectie van de rechter submandibulaire lymfeknopen. Vijf maanden na de ingreep werden er geen complicaties of recidieven vastgesteld.

\section{ABSTRACT}

In this case report, a seven-year-old, male, castrated European Shorthair diagnosed with a ranula is described. The patient was presented with a sublingual swelling on the right side, which was surgically treated with marsupialization and removal of the mandibular and sublingual salivary glands. Histopathological examination confirmed the diagnosis of a ranula and revealed the accidental resection of the right submandibualr lymph nodes. Five months after the operation, no complications or recurrences were observed.

\section{INLEIDING}

Sialocoeles of speekselmucocoeles ontstaan door lekkage van speeksel uit een beschadigde speekselklier of afvoergang (Smith, 2000; Radlinsky, 2013; Langley-Hobbs, 2014). De opstapeling van speeksel in bindweefsel lokt een inflammatoire reactie uit met de vorming van granulatieweefsel tot gevolg (Smith, 2000; Radlinsky, 2013; Langley-Hobbs, 2014). Een sublinguale sialocoele wordt ook een ranula genoemd. Daarnaastzijner cervicale, faryngeale en zygomatische sialocoeles.

Uit gerapporteerde gegevens blijkt dat de gemiddelde incidentie van speekselklieraandoeningen bij honden en katten ongeveer $0,3 \%$ is, waarbij honden vaker zijn aangetast dan katten (Brown, 1989; Spangler en Culbertson, 1991; Waldron en Smith, 1991; Hammer et al., 2001). Sialocoeles zijn de meest voorkomende afwijkingen van de speekselklieren.

Klinische symptomen van sialocoeles bij de hond of kat zijn afhankelijk van de locatie van de sialocoele. Sublinguale sialocoeles geven een fluctuerende, nietpijnlijke zwelling onder de tong. Er kunnen moeilijkheden bij eten, mondbloedingen, intermitterend braken, anorexie, ptyalisme en/of lethargie optreden (Radlinsky, 2013). Als een sublinguale of faryngeale sialocoele zeer groot is, kan deze ook anleiding geven tot respiratoire stridor (Kiefer en Davis, 2007; Dietens et al., 2011).

Ter behandeling van een sublinguale sialocoele zijn er vier opties en/of combinaties mogelijk: drainage (Kilic, 2009), injectie met cauteriserende/antiinflammatoire producten (Saifzadeh, 2004; Radlinsky, 2013), marsupialisatie (Lane, 2012) en sialoadenectomie (Radlinsky, 2013).

In deze casus wordt een volwassen kater met een ranula beschreven die succesvol behandeld werd met excisie van de speekselklier in combinatie met marsupialisatie. In de discussie wordt de regionale anatomie bij de kat besproken en wordt verder de nadruk gelegd op de diagnosestelling en chirurgische behandelingsopties van deze aandoening.

\section{CASUÏSTIEK}

Een zeven jaar oude, mannelijke, gecastreerde Europese korthaar van $6,6 \mathrm{~kg}$ werd aangeboden op de 


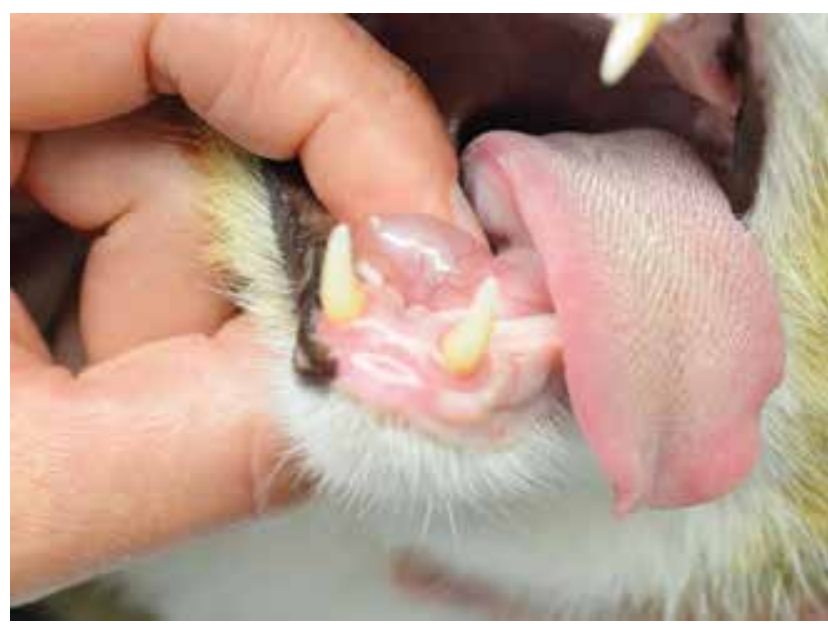

Figuur 1. Een zeven jaar oude, mannelijke, gecastreerde Europese korthaar werd aangeboden met een sublinguale zwelling aan de rechterkant.

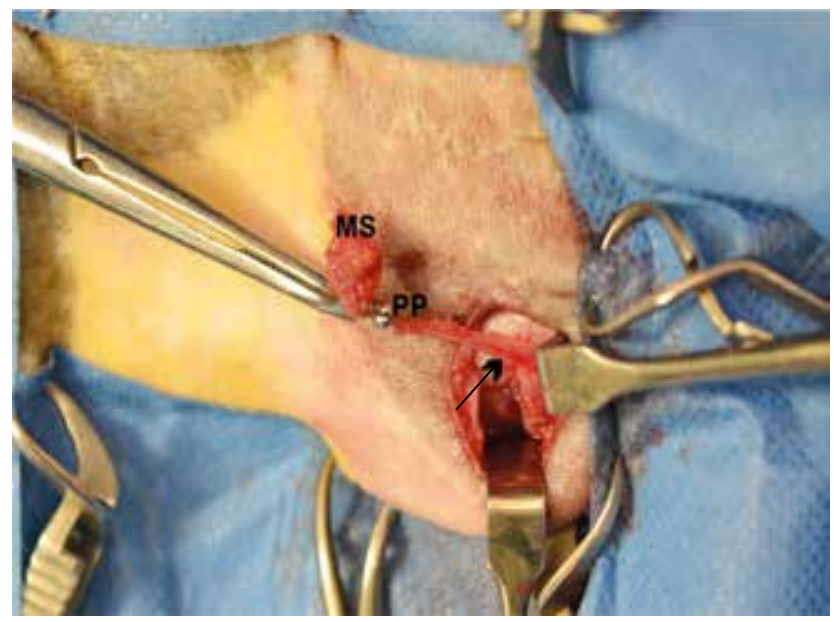

Figuur 2. Caudale tractie op de mandibulaire speekselklier (MS) met behulp van een weefselklem, zodat de afvoergang met aanpalende, sublinguale speekselklier (pars polystomatica, PP) gedisseceerd kon worden. De afvoergang (pijl) loopt verder in de diepte. De handretractor trekt de spierbuik van de musculus digastricus naar ventraal en zorgt zo voor een betere visualisatie. Rostraal is rechts.

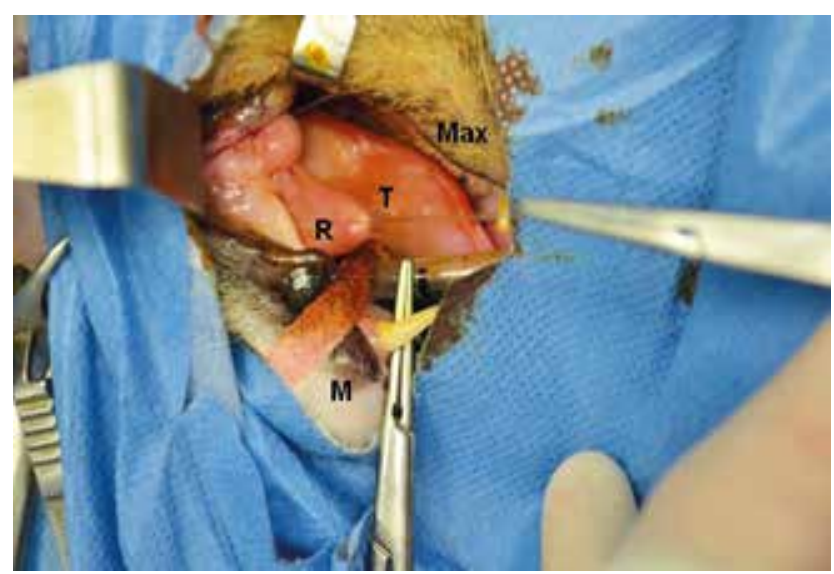

Figuur 3. Rechts lateraal aanzicht van open mond met steunhechting in het dak van de ranula (R). Onderzijde tong (T), maxilla (Max) en mandibula (M) worden weergegeven op de foto als oriëntatiepunten.
Faculteit Diergeneeskunde in Merelbeke (UGent) ter behandeling van een sublinguale intraorale zwelling rechts.

Reeds een week at de kat moeilijker waarbij hij zijn kop telkens naar links hield, drinken ging zonder problemen. De eigen dierenarts stelde een zwelling vast rechts onder de tong en stuurde de kat door na het opstarten van meloxicam $0,05 \mathrm{mg} / \mathrm{kg}$ (Loxicom $\AA$, Norbrook lab, Newry, Noord-Ierland) en pradofloxacine $5 \mathrm{mg} / \mathrm{kg}$ (Veraflox ${ }^{\circledR}$, Bayer, Leverkusen, Duitsland), beide orale suspensies. De ingestelde behandeling, die één week werd aangehouden, had geen effect op de grootte van de zwelling noch op het eetgedrag.

De kat was alert en een fluctuerende, niet-pijnlijke zwelling rechts onder de tong werd waargenomen (Figuur 1). Verder waren er geen afwijkingen, uitgezonderd een te hoge lichaamsconditiescore van 8 op 9.

Op basis van de anamnese en het lichamelijk onderzoek werd de waarschijnlijkheidsdiagnose van een ranula gesteld. Er werd geadviseerd om een marsupialisatie van de ranula en sialoadenectomie van de mandibulaire en sublinguale speekselklieren uit te voeren.

Een maand na het stellen van de diagnose werd de patiënt aangeboden voor de chirurgische correctie van de ranula. De kat werd intraveneus (IV) gepremediceerd met methadon $0,1 \mathrm{mg} / \mathrm{kg}$ (Comfortan ${ }^{\circ}$, Eurovet A.H., Bladel, Nederland) en dexmedetomidine $2 \mu \mathrm{g} / \mathrm{kg}$ (Dexdomitor $\AA$, Orion Corporation, Espoo, Finland). Vervolgens werd hij geïnduceerd met propofol $3 \mathrm{mg} / \mathrm{kg}$ IV (Propovet Multidose $\AA$, Abbott Lab, Berkshire, Verenigd Koninkrijk). Het onderhoud van de anesthesie gebeurde met isofluraan 1,3-1,5\% (Isoflo ${ }^{\circledR}$, Abbott Lab, Berkshire, Verenigd Koninkrijk) verdampt in $100 \% \mathrm{O}_{2}$. Gedurende de operatie werd bijkomende analgesie bekomen door middel van "constant rate infusion" (CRI) van fentanyl 5 $7 \mu \mathrm{g} / \mathrm{kg} / \mathrm{h}$ (Fentadon ${ }^{\circledR}$, Eurovet, Bladel, Nederland). Profylactisch werd cefazoline $20 \mathrm{mg} / \mathrm{kg}$ IV (Cefazo-

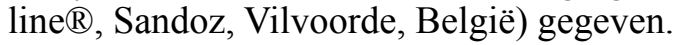

De rechter hals- en kopregio werden ruim geschoren. De patiënt werd in links laterale decubitus gepositioneerd met een opgerolde handdoek onder de nek. De operatieplaatsen, namelijk kaakregio en ranula, werden aseptisch voorbereid met povidone-jood-zeepoplossing (Vetclean $\AA$, Ecuphar, Oostkamp, België) en pure joodoplossing (Povidone dermicum $\AA$, Ecuphar, Oostkamp, België). De mandibulaire speekselklier werd gepalpeerd achter de kaaktak ter hoogte van de samenvloeiing van de rechter vena linguofacialis en vena maxillaris in de rechter vena jugularis externa. Op deze plaats werden de huid en subcutis van dorsaal naar ventraal ingesneden. Hemostase werd bekomen door middel van bipolaire elektrocoagulatie. Vervolgens werd de musculus platysma ingesneden en werd er stomp vrijgeprepareerd tot op het kapsel van de mandibulaire speekselklier. Het kapsel werd ingesneden en de speekselklier werd losgemaakt van het kapsel, waarbij mediaal gelegen bloedvaten werden gecoaguleerd. Door middel van caudale tractie op de mandibulaire speekselklier verliep de dissectie van 
de sublinguale speekselklier vlotter (Figuur 2). De afvoergang werd verder naar craniaal gevolgd langs de musculus digastricus tot de linguale zenuw geïdentificeerd kon worden. Ligatie en transectie van de ductus gebeurden net caudaal van de nervus lingualis. De sluiting van de wonde gebeurde in drie lagen. Eerst werd een doorlopende hechting uit polyglecaprone 25

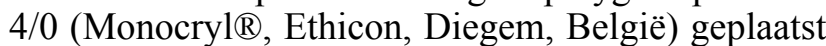
op de musculus platysma. Daarna werden met hetzelfde hechtmateriaal ook de subcutis (matrashechting) en de huid (intradermale hechting) gesloten.

Vervolgens werd overgegaan tot marsupialisatie van de ranula. Eerst werd een steunhechting geplaatst op het dak van de ranula (Figuur 3). Daarna werd een incisie gemaakt door de volledige dikte van de wand (Figuur 4). Het dak van de ranula werd verwijderd en de sectieranden van het granulatieweefselkapsel werden vastgehecht aan de mondmucosa door middel van twee doorlopende hechtingen van rostraal naar caudaal met polyglecaprone $255 / 0$. Alle verwijderde weefsels werden opgestuurd voor histopathologisch onderzoek.

$\mathrm{Na}$ de operatie werd de kat gehospitaliseerd. Postoperatieve analgesie werd bekomen met buprenorfine $0,02 \mathrm{mg} / \mathrm{kg}$ IV qid (Vetergesic ${ }^{\circledR}$, Alstoe, York, Verenigd Koninkrijk) en meloxicam 0,2 mg/kg subcutaan (SC) sid (Metacam ${ }^{\circledR}$, Boehringer Ingelheim Vetmedica, Ingelheim/Rhein, Duitsland). De antibioticumkuur met cefazoline $20 \mathrm{mg} / \mathrm{kg}$ tid werd aanvankelijk intraveneus verdergezet. Een dag na de operatie begon de kat te eten; hierna werd beslist dat hij de volgende dag naar huis mocht. Er werd aangeraden om thuis gedurende tien dagen zachte voeding aan te bieden (blikvoeding of geweekte korrels). De antibioticumbehandeling werd nog zeven dagen verdergezet met cefalexine $15 \mathrm{mg} / \mathrm{kg}$ per os bid (Therios ${ }^{\circledR}$, Sogeval Lab, Laval, Frankrijk) en meloxicam $0,05 \mathrm{mg} / \mathrm{kg}$ per os sid werd nog gedurende drie dagen toegediend om de pijn en ontsteking te onderdrukken.

Uit het histopathologisch onderzoek bleek dat naast de speekselklieren, bijhorende afvoergangen en het ranuladak, ook de submandibulaire lymfeknopen verwijderd waren. De speekselklieren en hun afvoergang vertoonden op het histologisch onderzoek een normaal aspect. In het weefselfragment van de mondmucosa, dat het dak van de ranula uitmaakte, waren uitmondingen van afvoergangen te zien. Ook werden fistelgangen met een uitgesproken pyogranulomateuze ontsteking opgemerkt. De lymfeknopen vertoonden uitgesproken lymfoïde hyperplasie met vorming van duidelijke kiemcentra en bevatten nesten van mastcellen die suggestief waren voor mastocytose of metastasen van een regionale primaire mastceltumor.

Twee weken na de operatie werd de patiënt ter controle aangeboden. De eigenaars meldden dat de kat thuis alert was en het eten en drinken vlot verliepen. Ongeveer een week na de operatie werd er eenmalig een beetje bloed gezien in de muil. Tijdens het algemeen lichamelijk onderzoek werden geen afwijkingen gevonden. Het operatielitteken ter hoogte

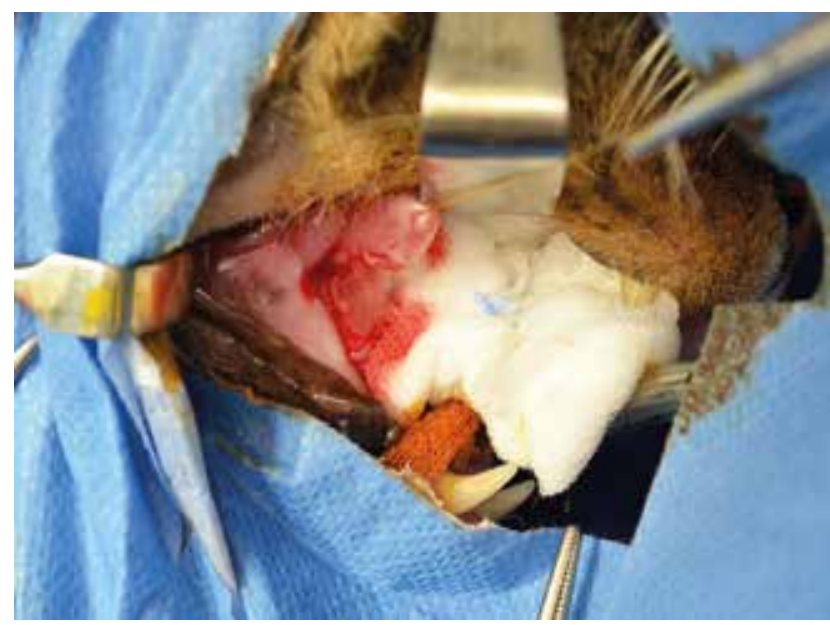

Figuur 4. Rechts lateraal aanzicht van open mond met een kompres ter absorptie van bloed en een steunhechting in de ranula. De volledige dikte van de sialocoelewand werd ingesneden.

van de huid was droog en gesloten. Ter hoogte van de kop of de nek werd geen oorzaak gevonden van de aanwezigheid van de mastcellen in de mandibulaire lymfeknopen.

De kat kwam vijf maanden postoperatief een laatste keer op controle. Er waren geen klinische klachten of recidieven van de ranula.

\section{DISCUSSIE}

Sublinguale sialocoeles ontstaan meestal ten gevolge van beschadiging van de sublinguale speekselklier of de afvoergang ervan, waarbij speeksel geaccumuleerd wordt in de mondbodem (Smith, 2000; Lane, 2012; Radlinsky, 2013; Langley-Hobbs, 2014). Doordat het vrijgekomen speeksel mild irriterend is vanwege de enzymen die er zich in bevinden, ontstaat er een ontstekingsreactie (Lane, 2012). In tweede instantie wordt granulatieweefsel gevormd. Het speeksel wordt op deze manier omkapseld zodat verdere migratie voorkomen wordt (Lane, 2012; Radlinsky, 2013).

Etiologieën van ranulae bij katten zijn nog niet volledig opgehelderd (Kiefer en Davis, 2007; Lane, 2012). Bovendien worden ze ook zelden geïdentificeerd. Hoewel trauma als belangrijkste oorzaak vooropgesteld wordt bij honden en katten, zijn er hiervoor meestal geen bewijzen (Lane, 2012; Radlinsky, 2013). Andere oorzaken die gesuggereerd worden zijn vreemde voorwerpen, stenose of obstructie van de speekselklierafvoergang en sialolieten (Bellenger en Simpson, 1992; Vallefuoco et al., 2011; Radlins$\mathrm{ky}, 2013)$. In deze casus was er een vermoeden van trauma, maar de exacte etiologie werd ook hier niet achterhaald.

De anatomie van de speekselklieren van katten is vrij beperkt en weinig gedetailleerd beschreven in de huidige literatuur. De anatomie van kop en speek- 

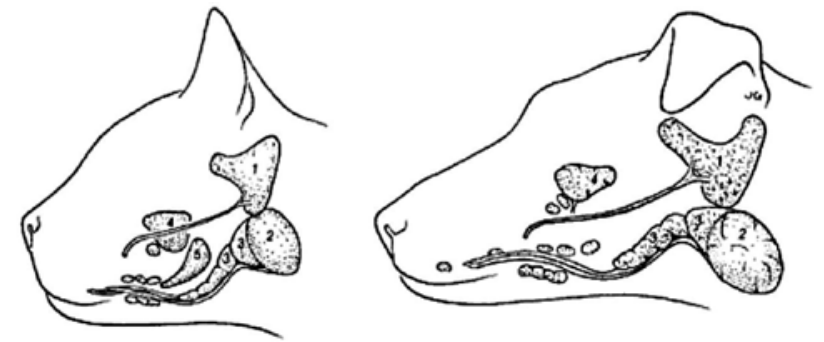

Figuur 5. Schematische voorstelling van de belangrijkste speekselklieren bij de kat (links) en de hond (rechts). 1. Parotis speekselklier; 2. Mandibulaire speekselklier; 3. Sublinguale speekselklier, pars monostomatica; 4. Zygomatische speekselklier; 5. Molaire speekselklier. De niet-geïdentificeerde speekselklier gelegen rondom afvoergangen van sublinguale en mandibulair klieren is de sublinguale speekselklier, pars polystomatica (uit: Dunning, 2003).

selklieren van de hond is daarentegen vakkundig onderzocht en uitgebreid beschreven. De algemene anatomische kenmerken zijn wel vermeld bij katten. Katten bezitten vijf paar speekselklieren: de glandulae parotis, mandibularis, sublingualis, zygomaticus en molaris (Figuur 5). Deze laatste is uniek voor de kat en komt niet voor bij de hond en evenmin bij de mens (Dunning, 2003; Kiefer en Davis, 2007; Langley-Hobbs, 2014). De parotisspeekselklier (ventraal van het oorkanaal), de glandula zygomaticus (tussen de jukboog en oogkas) en de glandula molaris (tussen lipmucosa en $\mathrm{m}$. orbicularis oris) met bijhorende afvoergangen kunnen weliswaar aanleiding geven tot een mucocoele maar zijn van geen belang bij het ontstaan van ranulae. De sublinguale speekselklier met bijhorende afvoergangen daarentegen liggen meestal aan de basis hiervan (Smith, 2000; Lane, 2012; Langley-Hobbs, 2014). De sublinguale speekselklier bij de hond en kat bestaat uit een pars monostomatica en een pars polystomatica. De lobuli van de pars monostomatica van de hond en kat hebben zich rond de mandibulaire en sublinguale afvoergang ter hoogte van de tongwortel georganiseerd. De sublinguale speekselklier pars monostomatica bestaat bij de hond uit een caudaal en rostraal deel. Het caudale deel is verbonden en ligt in een gemeenschappelijk bindweefselkapsel met de mandibulaire speekselklier (Peeters, 1991). Beide delen van de pars monostomatica van de sublinguale speekselklier draineren in één sublinguale afvoergang (Peeters, 1991; Dunning, 2003). De lobuli van de sublinguale speekselklier, pars polystomatica, zijn kleiner en komen meer verspreid voor. Daarenboven hebben ze aparte uitmondingen in kleine individuele sublinguale afvoergangen tussen de tong en de mandibula (laterale sublinguale recessus) (Dunning, 2003). De mandibulaire speekselklier, mediaal van de ventrale rand van de parotisklier en caudaal van $\mathrm{m}$. masseter, ligt zoals hoger vermeld in een gemeenschappelijk kapsel met de pars monostomatica van de sublinguale speekselklier (Walker, 1982; Langley-Hobbs, 2014). Bij honden liggen de speek- selklieren in het gemeenschappelijke kapsel tussen de linguofaciale en maxillaire vene terwijl bij katten de venen samenkomen op de laterale zijde van de klieren (Dunning, 2003). De mandibulaire afvoergang vertrekt zowel bij de hond als de kat aan de rostromediale zijde van de respectievelijke klier en loopt parallel met de ductus sublingualis. Beide lopen verder naar rostraal tussen de tongspieren naar de mondbodem. Daar monden ze in de meeste gevallen via afzonderlijke openingen uit in een gezamenlijke papil, namelijk de sublinguale karunkel, lateraal van het tongfrenulum (Walker, 1982; Dunning, 2003; LangleyHobbs, 2014). Bij sommige honden is er een kleine sublinguale papil naast de mandibulaire papil op te merken (Peeters, 1991).

Walker (1982) wees erop om een duidelijk onderscheid te maken tussen de mandibulaire speekselklier (gelobuleerde structuur) en de lymfeknopen (kleiner en gladder) in deze regio. Effectief blijkt dit in praktijk niet altijd zo eenvoudig. In deze casus was er immers tijdens de chirurgie ook onduidelijkheid over de aard van de verschillende weefsels. Naast de mandibulaire speekselklier werden ook de lymfeknopen verwijderd, gezien het veranderde aspect van de lymfeknopen.

De waarschijnlijkheidsdiagnose van een ranula werd bij deze kat gesteld op basis van de anamnese en het klinisch onderzoek. De differentiaaldiagnosen voor een sublinguale zwelling zijn ranula, cyste, abces, vreemd voorwerp met granuloomvorming, hematoom, oedeem secundair aan een allergische reactie en neoplasie (Kiefer en Davis, 2007; Samanta, 2012). Gezien de zwelling zacht, fluctuerend en niet-pijnlijk was, was een sublinguale sialocoele of cyste het meest waarschijnlijk. Een neoplasie kan soms echter ook zacht en fluctuerend zijn (Radlinsky, 2013). Om zekerheid te bekomen omtrent de inhoud van de sublinguale zwelling wordt deze idealiter steriel geaspireerd. Macroscopisch wordt bij een sialocoele een heldere, mucoïde, goudgele vloeistof verwacht, eventueel met bloedbijmenging (Kiefer en Davis, 2007; Langley-Hobbs, 2014). Het cytologisch beeld van een sialocoele-aspiraat is meestal celarm (Kiefer en Davis, 2007; Langley-Hobbs, 2014). Secretorische epitheelcellen, gevacuoliseerde macrofagen, rode bloedcellen en/of neutrofielen zijn cellen die kunnen voorkomen. Afhankelijk van het stadium, acuut of chronisch, zijn er respectievelijk meer neutrofielen of hematoïdine kristallen. Deze laatste komen vrij bij de afbraak van oude, rode bloedcellen en duiden op voorgaande bloeding(en) (Allison en Maddux, 2008; Dietens et al., 2011). Een bijkomende "periodic acidSchiff" (PAS)-kleuring, een specifieke mucuskleuring, kan uitgevoerd worden om de aanwezigheid van speeksel te bevestigen (Radlinsky, 2013). Speekselkliercysten en sommige sublinguale neoplasieën kunnen gelijkaardige bevindingen geven op cytologie en PAS-kleuring. Histopathologisch onderzoek blijft aangewezen om een definitieve diagnose te stellen (Radlinsky, 2013). 
Voor de behandeling van sublinguale sialocoeles bij katten zijn er verschillende opties zoals drainage van de sialocoele, injectie met cauteriserende/antiinflammatoire producten, marsupialisatie of het verwijderen van de betrokken speekselklieren. Het is ook mogelijk om enkele van de bovenstaande technieken te combineren (Kiefer en Davis, 2007; Radlinsky, 2013; Langley-Hobbs, 2014). Drainage van de ranula als enige behandeling leidt in veel gevallen tot recidieven (Kiefer en Davis, 2007; Kilic, 2009; Langley-Hobbs, 2014). Zowel herhaaldelijke drainage als injectie met cauteriserende of anti-inflammatoire producten pakt de oorzaak van de sialocoele niet aan. Daarenboven kunnen ze leiden tot abcedatie en fibrose, waardoor de daaropvolgende chirurgie bemoeilijkt wordt (Saifzadeh 2004; Radlinsky, 2013).

Marsupialisatie is een chirurgische techniek die typisch toegepast wordt bij sublinguale sialocoeles om de drainage van speeksel in de mondholte te bekomen (Dunning, 2003). De gesloten holte wordt geconverteerd naar een open zakje door een gedeelte van de sialocoelewand weg te snijden en de granulatieweefselrand aan de mondmucosa te hechten (Dunning, 2003, Kiefer en Davis, 2007; Radlinsky, 2013). Gezien het gering aantal beschreven casussen van sublinguale sialocoeles bij katten, zijn er maar weinig gegevens omtrent de prognose na marsupialisatie. In een retrospectieve studie van Kiefer en Davis (2007) bleek er geen recidief te zijn bij twee katten die louter met marsupialisatie werden behandeld. Theoretisch bestaat de mogelijkheid op recidief van de ranula wanneer de geopende sialocoele zich opnieuw sluit (Kilic, 2009). Hoewel marsupialisatie van de sublinguale sialocoeles als monotherapie effectief kan zijn, wordt er in de literatuur bij ranulae bij honden aangeraden om de veroorzakende speekselklier(en) ook te verwijderen (Kiefer en Davis, 2007; Radlinsky, 2013). De kans op recidief wordt zo tot een minimum beperkt. Bij de kat van de voorliggende casus werd een combinatie van marsupialisatie en sialoadenectomie van de mandibulaire en sublinguale speekselklier uitgevoerd. Beide speekselklieren worden steeds samen verwijderd omdat de sublinguale speekselklier nauw verbonden is met de mandibulaire alsook met zijn afvoergang. Verwijdering van de ene zou immers schade kunnen toebrengen aan de andere (Radlinsky, 2013; Langley-Hobbs, 2014). Postoperatieve xerostomia (droge mond) wordt bij de kat of de hond niet beschreven, zelfs niet na bilaterale verwijdering van mandibulaire en sublinguale speekselklieren, vermoedelijk omdat er zelfs dan nog steeds meerdere speekselklieren aanwezig zijn. Als alternatief was de combinatie van speekselklierexcisie met eenvoudige drainage van de sialocoele ook mogelijk geweest. Deze techniek is beschreven bij honden (Radlinsky, 2013).

Er zijn twee methoden bij de hond en de kat voor het uitvoeren van sialoadenectomie van de mandibulaire en sublinguale speekselklier. Enerzijds is er de traditionele, laterale benadering (Lane, 2012), die toegepast werd in deze casus. Hierbij wordt het speeksel- klierpakket net caudaal van de nervus lingualis geligeerd. Anderzijds is er de ventrale benadering waarbij het volledige klierpakket verwijderd kan worden tot juist ventraal van de sublinguale karunkel (Ritter et al., 2007; Lane, 2012).

In een studie van Lane (1994) werden 166 honden met faryngeale, cervicale of sublinguale sialocoeles en zeven katten met sublinguale sialocoeles opgenomen (Lane, 2012). Vier katten werden behandeld via de laterale en drie via de ventrale benadering. In alle zeven gevallen werden geen recidieven of complicaties beschreven. Bij de 166 honden werd 7\% recidieven of persisterende sialocoeles opgemerkt na een correct uitgevoerde laterale sialoadenectomie. Met de ventrale benaderingstechniek (60 operaties) werden geen recidieven of persisterende sialocoeles beschreven (Lane, 1994; Ritter et al., 2006). De toegangsruimte gevormd door de caudale rand van de mandibula, de vena linguofacialis en vena jugularis is nauw bij de laterale benadering. Hierdoor is de dissectie van het speekselklierpakket tussen de tongspieren gecompliceerd. De meest rostrale lobuli van de pars polystomatica van de sublinguale speekselklier blijven bijna onvermijdelijk achter. Indien deze de oorzaak zijn van de sialocoele, wat bij deze recidieven ook het geval was, persisteert de sialocoele (Lane, 2012). Bij de ventrale techniek wordt de gehele klier blootgelegd en verwijderd. Dit is de reden waarom er bij het mislukken van de laterale techniek, de ventrale techniek een goede oplossing biedt (Lane, 2012). De nadelen van deze laatste techniek zijn een invasievere chirurgie, een grotere incisie en een langere operatieduur (Lane, 2012).

Complicaties na sialoadenectomie bij honden zijn weinig frequent (Tobias, 2010). Het recidiveren van mucocoeles en seroomvorming zijn het meest voorkomend (Radlinsky, 2013). Oorzaken van recidieven van sialocoeles zijn: behandeling van de verkeerde zijde, onvoldoende wegname van speekselklierweefsel en het wegnemen van de lymfeknopen in plaats van de klieren door bijvoorbeeld een beperkte anatomische kennis (Lane, 2012; Radlinsky, 2013). In een studie van Ritter et al. (2006) waarbij honden met ventrale sialoadenectomie werden behandeld, trad er in $17 \%$ van de gevallen seroomvorming op. Een seroom kan zich vormen door de ontstane dode ruimte en de beweeglijke regio ter hoogte van de incisie (Ritter et al., 2006; Radlinsky, 2013). Drainage of aspiratie ervan is niet nodig, tenzij de patiënt er last van ondervindt. Immers, een seroom resorbeert normaliter 10 tot 14 dagen postoperatief uit zichzelf (Lane, 2012; Radlinsky, 2013). Speekselklierexcisie is een propere operatie. Het respiratoire of gastro-intestinale stelsel wordt immers niet geopend. Een normale, aseptische operatietechniek is dan meestal ook voldoende om infecties te vermijden (Lane, 2012; Radlinsky, 2013). In de literatuur zijn er geen gevallen bij honden of katten beschreven van abcedatie na speekselklierexcisie (Lane, 2012). In deze casus werd de antibioticatherapie postoperatief gedurende tien dagen verdergezet. 
Retrospectief gezien was er geen indicatie voor zo'n lange antibioticabehandeling. Profylactisch antibioticumgebruik om de kolonisatie van bacteriën te voorkomen zou zelfs niet nodig geweest zijn. Ter hoogte van de mond verzorgt speeksel immers een goede aspecifieke afweer (Soukup, 2009) en sialoadenectomie is een propere operatie.

Bij voorkeur worden de verwijderde weefsels histopathologisch onderzocht ter uitsluiting van neoplasie als oorzaak van de sialocoele (Radlinsky, 2013). Ook in deze casus werden de verwijderde weefsels onderzocht. Aan de speekselklieren en afvoergangen waren er geen abnormaliteiten. Ter hoogte van het dak van de ranula werden fistelgangen met een uitgesproken pyogranulomateuze ontsteking opgemerkt. Deze ontstonden vermoedelijk ten gevolge van automutilatie wanneer de kat op de ranula beet. Verder bleek dat er naast speekselklieren ook lymfeknopen werden verwijderd. In de lymfeknopen werden er naast lymfoïde hyperplasie met vorming van kiemcentra, nesten van mastcellen aangetroffen. De lymfoïde hyperplasie is allicht het rechtstreekse gevolg van de ontstekingsreactie ter hoogte van de ranula, terwijl de aanwezigheid van clusters mastcellen in de lymfeknoop wordt aanschouwd als een toevalsbevinding, aangezien er geen oorzakelijk verband met sialocoeles bestaat.

De prognose na de chirurgische behandeling van een sialocoele is uitstekend, op voorwaarde dat een juiste diagnose wordt gesteld en dat er een accurate en volledige speekselklierexcisie wordt uitgevoerd (Radlinsky, 2013). De prevalentie van recidieven na sialoadenectomie is laag, namelijk $\leq 7 \%$ (Lane 1994; Dunning 2003), tenminste als de betrokken speekselklieren volledig verwijderd werden. Bij de kat uit de huidige casus werd op het controlebezoek, vijf maanden na de ingreep, geen nieuwe ranulavorming vastgesteld.

\section{CONCLUSIE}

Een ranula bij een kat is een zeldzaam voorkomende aandoening. De waarschijnlijkheidsdiagnose kan gesteld worden op basis van de anamnese en het lichamelijk onderzoek. Een histopathologisch onderzoek blijft echter noodzakelijk om een cyste of neoplasie uit te sluiten. De prognose na sialoadenectomie is zeer goed. In de literatuur wordt er geen recidief gerapporteerd. Het aantal beschreven gevallen bij katten behandeld met sialoadenectomie is echter beperkt.

\section{REFERENTIES}

Allison R.W., Maddux J.M., (2008). Subcutaneous glandular tissue: mammary, salivary, thyroid, and parathyroid. In: Cowell R.L., Tyler R.D., Meinkoth J.H., DeNicola D.B. (editors). Diagnostic Cytology and Hematology of the Dog and Cat. Third edition, Mosby Elsevier, St. Louis, 112-129
Bellenger C.R., Simpson D.J., (1992). Canine sialocoeles60 clinical cases. Journal of Small Animal Practice 33, 112-129

Brown N.O., (1989). Salivary gland diseases. Diagnosis, treatment, and associated problems. Problems in Veterinary Medicine 1, 281-294

Chaudhari K.S., Moru N.H., Tatelu S.R., Khandekar G.S., Raut S.S., Patil D.J., (2010). Salivary cyst in a cat: a case report. Veterinary World 3, 129

Dietens A., Spanoghe I., Paepe D., Van der Vekens E., Vercauteren G., Bosmans T., de Rooster H., (2011). Faryngealesialocele bij een hond. Vlaams Diergeneeskundig Tijdschrift 80, 233-239

Dunning D., (2003). Oral cavity: tong, lips, cheeks, pharynx, and salivary glands. In: Slatter D. (editor). Textbook of Small Animal Surgery. Third edition, Elsevier Health Science, Philadelphia, 553-560

Hammer A., Getzy D., Ogilvie G., Upton M., Klausner J., Kisseberth W.C., (2001). Salivary gland neoplasia in the dog and cat: survival times and prognostic factors. Journal of the American Animal Hospital Association 37, 478-482

Juergens T., Hjelm G.K., Lange R.L., (1974). Mandibular sialoadenectomy. Iowa State University Veterinarian 36, 94-98

Kiefer K.M., Davis G., (2007). Salivary mucoceles in cats: A retrospective study of seven cases. Veterinary Medicine 102, 582-587

Kilic N., (2009). Surgical management of sublingual sialocele in dogs. The Indian Veterinary Journal 86, 613-615

Lane J.F., (1994). Surgical options in the treatment of salivary mucocoeles. In: Proceedings of 19th Congress of World Small Animal Veterinary Association, 568-572

Lane J.F., (2012). Surgical treatment of sialocoeles. In: Verstraete F.J.M., Lommer M.J. (editors). Oral and Maxillofacial Surgery in Dogs and Cats. Saunders-Elsevier, London, 501-510

Langley-Hobbs S.J., (2014). Head. In: Langley-Hobbs S.J., Demetriou J.L., Ladlow J.F. (editors). Feline Soft Tissue and General Surgery. Saunders Elsevier, UK, 571- 586

Peeters M.E., (1991). De behandeling van speekselcysten bij hond en kat. Tijdschrift voor Diergeneeskunde 116, 169-172

Radlinsky M.G., (2013). Surgery of the digestive system. In: Fossum T.W. (editor). Small Animal Surgery. Fourth edition., Elsevier, St. Louis, 417- 422

Ritter M.J., von Pfeil D.J.F., Stanley B.J., Hauptman J.G., Walshaw R., (2006). Mandibular and sublingual sialocoeles in the dog: A retrospective evaluation of 41 cases, using the ventral approach for treatment. New Zealand Veterinary Journal 54, 333-337

Saifzadeh S., (2004). Sublingual sialocele (ranula) in a German sherpherd dog. Iranian Journal of Veterinary Research 5, 117-121

Samanta G., (2012). Sublingual sialocele in a domestic cat and its successful surgical management. Exploratory Animal and Medical Research 2, 179-181

Smith M.M., (2000). Oral and salivary gland disorders. In: Ettinger S.J., Feldman E.C. (editors). Textbook of Veterinary Internal Medicine. Fifth edition., W. B. Saunders Co. Philadelphia, 1119-1121

Soukup J.W., (2009). Periodontitis. In: Ettinger S.J., Feldman E.C. (editors). Textbook of Veterinary Internal Medicine. Seventh edition, Saunders-Elsevier, St. Louis, $179-185$ 
Spangler W.L., Culbertson M.R., (1991). Salivary gland disease in dogs and cats: 245 cases (1985-1988). Journal of the American Veterinary Medical Association 198, 465-469

Tobias K.M., (2010). Sialoceles. In: Tobias K.M. (editor). Manual of Small Animal Soft Tissue Surgery. First edition, Wiley-Blackwell, Singapore, 393-399

Vallefuoco R., Jardel N., El Mrini M., Stambouli F., Cordonnier N., (2011). Parotid salivary duct sialocele asso- ciated with glandular duct stenosis in a cat. Journal of Feline Medicine and Surgery 13, 781-783

Waldron D.R., Smith M.M., (1991). Salivary mucoceles. Problems in Veterinary Medicine 3, 270-276

Walker W. F., (1982). The coelom and the 7 digestive and respiratory systems. In: Brown M., Field C., Boehme B., Rzasa C.B. (editors). A Study of the Cat with Reference to Human Beings. Fourth edition, CBS College Publishing, New York, 147-168

Therapie-resistente idiopathische epilepsie bij de hond: en nu?

\section{Patiënten gezocht voor}

\section{onderzoek naar de doeltreffendheid van rTMS}

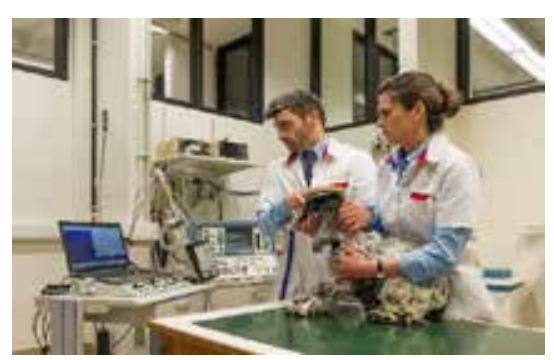

Ongeveer één derde van de honden met idiopathische epilepsie heeft een slechte aanvalscontrole met de ingestelde medicamenteuze behandeling (aan de hoogste dosis en/of aan de juiste serumconcentraties). Voor deze therapie-resistente of refractaire honden hebben we vandaag de dag, jammer genoeg, geen behandelingsopties meer ter beschikking die hun doeltreffendheid reeds hebben bewezen.

Naar analogie met de humane geneeskunde willen we bij deze patiëntengroep graag het anti-epileptisch effect van repetitieve transcraniële magnetische stimulatie (rTMS) nagaan. Dit is een niet-pijnlijke, niet-invasieve manier van neurostimulatie en wordt bij de mens in wakkere toestand uitgevoerd. Bij honden is echter een lichte sedatie aangewezen (hond moet gedurende 1 uur stilliggen). Uit humane studies is gebleken dat magnetische stimulatie van de hersenen bij bepaalde patiënten kan leiden tot een betere aanvalscontrole.

Dit is de eerste grootschalige studie die zal uitgevoerd worden bij de hond wereldwijd.

Voor meer informatie, gelieve contact op te nemen met:

Dr. Sofie Bhatti sofie.bhatti@ugent.be

Dr. Marios Charalambous marios.charalambous@ugent.be Prof. Dr. L. Van Ham

Universiteit Gent, Faculteit Diergeneeskunde, Vakgroep Kleine Huisdieren - Neurologie Epicentrum, Salisburylaan 133, B-9820 Merelbeke, België 